\title{
Study of knowledge, attitude and practices of contraception in breast- feeding mothers
}

\author{
Aiyleen Shiza Shawl*, Vidya Thobbi
}

Department of Obstetrics and Gynecology, Al-Ameen Medical College and Hospital, Bijapur, Karnataka, India

Received: 08 February 2019

Accepted: 06 March 2019

\section{*Correspondence:}

Dr. Aiyleen Shiza Shawl,

E-mail: soulfulshiza@gmail.com

Copyright: (C) the author(s), publisher and licensee Medip Academy. This is an open-access article distributed under the terms of the Creative Commons Attribution Non-Commercial License, which permits unrestricted non-commercial use, distribution, and reproduction in any medium, provided the original work is properly cited.

\begin{abstract}
Background: In India, as in many other countries, postpartum family planning is usually initiated after 6 weeks postpartum. Early resumption of sexual activity coupled with early and unpredictable ovulation leads to many unwanted pregnancies in the first year postpartum. Increase in hospital deliveries provides an excellent opportunity to sensitize women and provide effective contraception. Hence the present study was done at our tertiary care centre to assess the knowledge, attitude, practice regarding contraception and to find out the relationship between knowledge and attitude regarding contraception among breast feeding mothers.

Methods: A hospital based observational study. The patients admitted at our tertiary care centre in the Department of Obstetrics and Gynecology.

Results: Majority of the participants (72\%) were in the age group of $21-25$ years. $21.2 \%$ of the study group was educated up to primary level while $33.2 \%$ and $18.4 \%$ of the participants studied till SSC and HSC respectively. Majority of participants were from middle class (50\%) followed by lower class $(36.4 \%)$ and upper class $(13.6 \%)$. $69.6 \%$ participants resided in rural areas while $30.4 \%$ participants were from urban areas. It was observed that age, education and mode of delivery were the significant factors.

Conclusions: As the government gives incentives to couples who opt for permanent sterilization, which is an effective drive, it should also give incentives to couples who follow temporary methods and delay pregnancies. Couples who adopt one child norm or 2 children norm should be encouraged by benefits either in the form of children's education or health insurance.
\end{abstract}

Keywords: Breast feeding, Millennium development goals, National rural health mission

\section{INTRODUCTION}

As a signatory nation India is committed to achieve Millennium Development Goals (MDG). Improving the maternal and child health and their survival is central to achievement of national heath goals under National Rural Health Mission as well as MDG 4 and 5. ${ }^{1}$ The current infant mortality rate (IMR) of India is 41 per 1000 live births as compared to developed countries such as United kingdom, Canada, United states with current IMR of 4, 5, 6 per 1000 live births respectively. $^{2}$ Mother with exclusive breastfeeding for 6 months and continuing breastfeeding for 12 months with food supplements have proven to reduce infant mortality rate. ${ }^{3}$ Breast feeding protects babies and infants from infections, chronic diseases such as diarrhoea and acute respiratory diseases. Maternal and child care services are considered to be the key elements in the primary health system of a country which aims for a healthy society. ${ }^{1,3}$ However, even in the era of globalization mother and child care still lags behind in many regions of the world and especially the under developed or developing countries. In India, also 
the utilization of maternal and child care is only 60 percent in rural areas. ${ }^{4}$ Antenatal care has been routine practice throughout the world since early in the twentieth century. ${ }^{2,4}$

Each year, more than 100 million women worldwide make decisions about the use of a method of contraception after childbirth. ${ }^{1}$ These decisions include not only making a choice regarding a contraceptive method but also deciding the best time for initiation of the chosen method. These decisions may be more complex for breastfeeding women, because both the choice and timing of hormonal methods of contraception may affect both milk production and infant growth and development. $^{2}$

The need of contraceptive practices in order to control population explosion lies in the following point:

- To avoid unwanted births

- To regulate intervals between pregnancies

- To control the time at which births occur in relation to age of the parent

- To determine the number of children in family

Family planning through contraception tries to achieve two main objectives; firstly, to have only the desired number of children and secondly, to have these children by proper spacing of pregnancies. ${ }^{5,6}$

Contraception methods by definition means to prevent unwanted pregnancy by temporary or permanent methods. ${ }^{7}$ India is second largest populated country in the world accounting for $17.5 \%$ of world's population by adding around 25 million births every year, $65 \%$ of women in the first year postpartum have an unmet need for family planning. ${ }^{8,9}$ In India, as in many other countries, postpartum family planning is usually initiated after 6 weeks postpartum. Early resumption of sexual activity coupled with early and unpredictable ovulation leads to many unwanted pregnancies in the first year postpartum.

Thus, immediate postpartum family planning services need to be emphasized wherein the woman leaves the hospital with an effective contraception in place. Increase in hospital deliveries provides an excellent opportunity to sensitize women and provide effective contraception along with delivery services. Although, family planning and reproductive health programs have contributed immensely to a global decline in the incidence of unintended pregnancy; however, the rates are still very high in some developing countries. ${ }^{10}$

In view of high rate of unintended pregnancy in our country, these women need effective long-term contraception to allow them a reliable means of child spacing. In India $65 \%$ of women in first year postpartum have an unmet need for family planning. As in immediate postpartum period women is known not to be pregnant and setting may be convenient for both provider and women. Immediate use of contraception could fulfil a long-standing need for a simpler, less expensive, immediately reversible and effective, long term contraception, which does not interfere with breast feeding. In India, CopperT380A is being supplied free of cost by the government, to all health centres and private practitioners. This device is a proven highly effective and reversible spacing method of interval contraception, with effective protection for 10 years

The importance of having healthy spacing of pregnancy in India is emphasized by the fact that approximately $27 \%$ of births occur in less than 24 month after previous birth and have a higher risk of adverse outcome like abortions, premature labour, postpartum haemorrhage, low birth weight babies, fetal loss and maternal death.

Hence the present study was done at our tertiary care centre to assess the knowledge, attitude, practice regarding contraception among breast feeding mothers and to find out the relationship between knowledge and attitude regarding contraception among breast feeding mothers. The aim of the present study was to assess the knowledge regarding contraception among breast feeding mothers, to assess the attitude regarding contraception among breast feeding mothers, to assess the practice regarding contraception among breast feeding mothers, to find out the relationship between knowledge and attitude regarding contraception among breast feeding mothers.

\section{METHODS}

A hospital-based study was conducted with 500 breast feeding mothers to assess the knowledge, attitude and practice regarding contraception among breast feeding mothers.

The Study type was in a hospital based observational study. Source of data generated from the patients admitted at our tertiary care centre in the Department of Obstetrics and Gynecology. The study duration was of 2 Years

\section{Study population}

All breast-feeding mothers to assess the knowledge, attitude and practice regarding contraception among breast feeding mothers admitted at our tertiary care centre in the Department of Obstetrics and Gynecology.

\section{Sample size}

500 Breast Feeding mothers.

Considering a confidence level of $95 \%$ and confidence interval of 4.4 the number of participants in present study to achieve statistical significance is 496. This was calculated by Survey System. The Survey System ignores the population size when it is "large" or unknown. 
Population size is only likely to be a factor when you work with a relatively small and known group of people (e.g., the members of an association). Hence a sample size of 500 was considered adequate for present study.

\section{Inclusion criteria}

- Who are rearing the baby and admitted in postnatal ward

- Present during the period of data collection

- Desire to use contraception.

\section{Exclusion criteria}

- Mothers who were not willing to participate in the study.

\section{Methodology}

The present study was conducted at The Department of Obstetrics and Gynaecology, Vijayapur during the period from November 2016 to June 2018. Knowledge and attitude of the patients who were admitted in the Department of Obstetrics and Gynecology. The dependant variables were knowledge, attitude, practice and preferences of contraceptive methods. The independent variables were age, age at marriage, religion, educational status, occupation, duration of marriage, number of pregnancies, number of living children, type of family, income and source of information.

- Formal permission from the admitted patient.

- Investigator introduces herself to the subject.

- Administration of structured questionnaire to assess the knowledge and attitude regarding contraception among breast feeding mothers.

The respondents were interviewed using a translated language tool consisting of a demographic Performa, structured knowledge questionnaire, structured attitude scale and opinionnaire on practice and preferences of contraceptive methods.

\section{Instruments}

- Structured interview schedule to assess the knowledge about contraception.

- Structured interview schedule to assess the attitude about contraception

- Structured interview schedule to assess the practice about contraception

Considering the sentimental issue of contraception and sensitivity of the topic the interview was conducted on individual basis. Information was collected regarding her age, education, husband's education, religion, per capita income, age at marriage, number of living children, husband wife discussions, sex of living children, desire for more children, influence by elders and religious decisions. This was followed by mass education and counselling for a group of around 10-15 women regarding various suitable methods of contraception with the help of Audio-visual aids. The advantages and drawbacks were explained, and patients were offered "cafeteria approach" to use any contraceptive method they wanted.

\section{Statistical analysis}

Quantitative data is presented with the help of Mean and Standard deviation. Qualitative data is presented with the help of frequency and percentage table. Association among the study groups is assessed with the help of Odds Ratio test. 'p' value less than 0.05 is taken as significant. Results were graphically represented where deemed necessary. Appropriate statistical software, including but not restricted to MS Excel, SPSS ver. 20 will be used for statistical analysis. Graphical representation will be done in MS Excel 2010.

\section{RESULTS}

Majority of the participants (72\%) were in the age group of 21-25 years followed by $20 \%$ in the age group of 26 30 years, $4.4 \%$ in the age group of $\geq 30$ years and $3.6 \%$ in the age group of $\leq 20$ years (Figure 1 ).

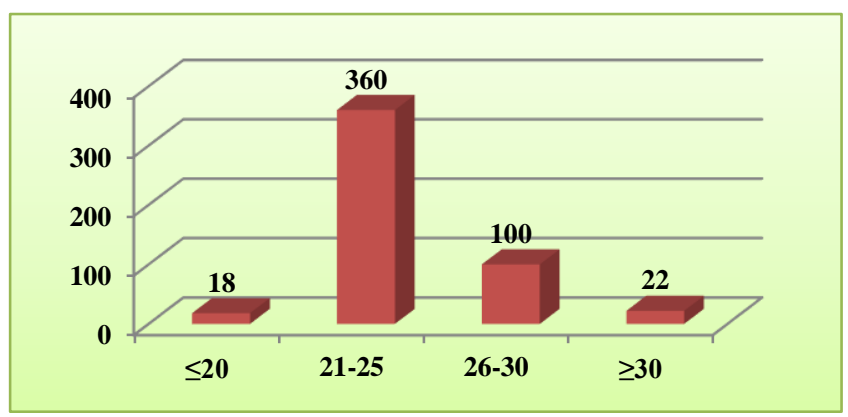

Figure 1: Age (years).

$21.2 \%$ of the study group was educated up to primary level while $33.2 \%$ and $18.4 \%$ of the participants studied till SSC and HSC respectively. $15.2 \%$ of the study population was graduates and $12 \%$ participants had no education (Figure 2).

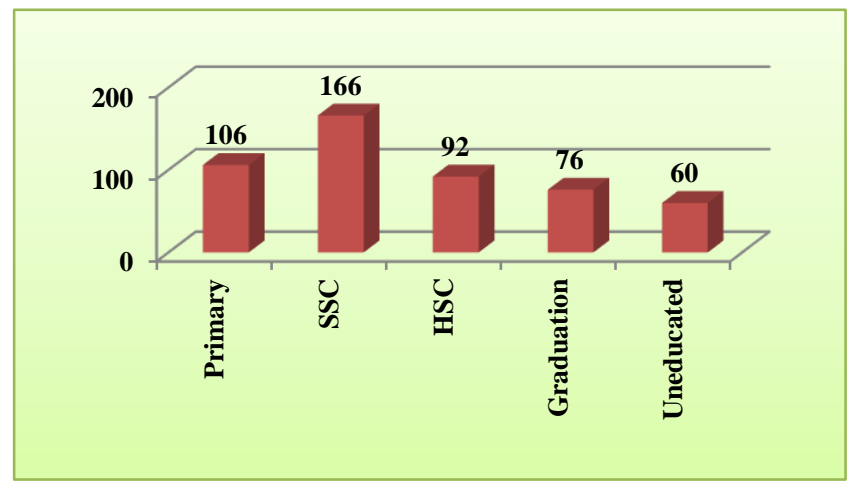

Figure 2: Education. 
Majority of participants were from middle class $(50 \%)$ followed by lower class (36.4\%) and upper class (13.6\%) (Figure 3).

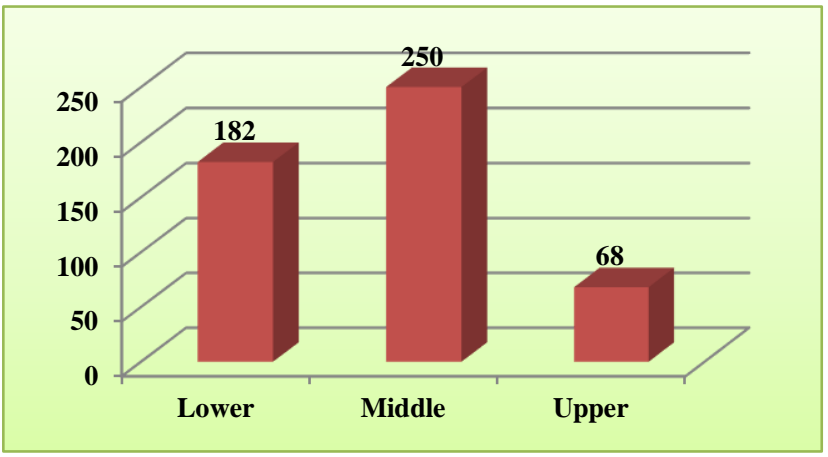

Figure 3: Socio-economic status.

$69.6 \%$ participants resided in rural areas while $30.4 \%$ participants were from urban areas (Figure 4).

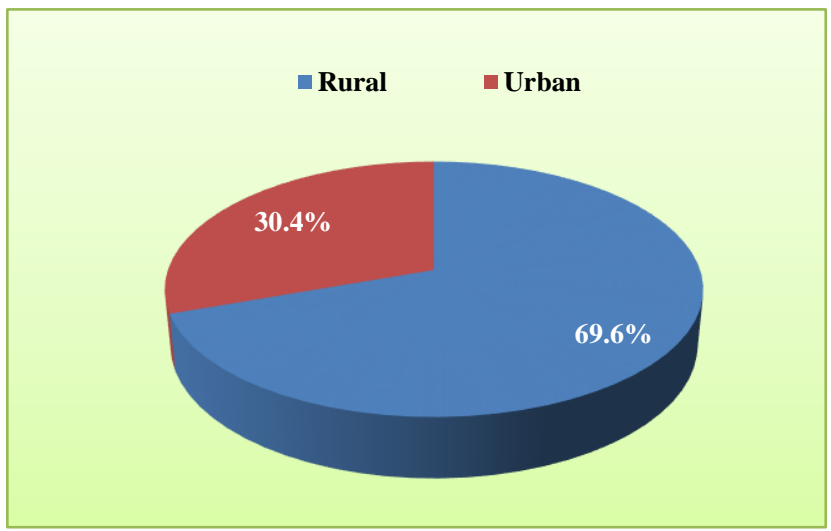

Figure 4: Residential Area

$410(82 \%)$ participants were booked cases while 90 $(18 \%)$ participants were unbooked cases. $230(46 \%)$ participants were primigravida while $270 \quad(54 \%)$ participants were multigravida.

Majority of the participants (93.2\%) were between $37-41$ weeks of gestational age at delivery followed by $6 \%$ participants in $<37$ weeks and $(0.8 \%)$ participants in $>41$ weeks. Delivery route was Vaginal in $38.8 \%$ cases and Caesarean Section was performed in $61.2 \%$ cases. $81 \%$ participants had heard of contraception of which $42 \%$ knew what contraception means. $32 \%$ participants were aware of when contraception after delivery should be started. $40 \%$ participants correctly answered about different contraceptive methods (Figure 5)

45\% participants knew about contraception from the health institution while $24 \%$ and $18 \%$ participants heard about it from educational institution and mass media respectively. $13 \%$ participants knew about contraception from others (Figure 6). 66\% and 18\% participants had said they would select temporary and permanent contraception method while respectively.

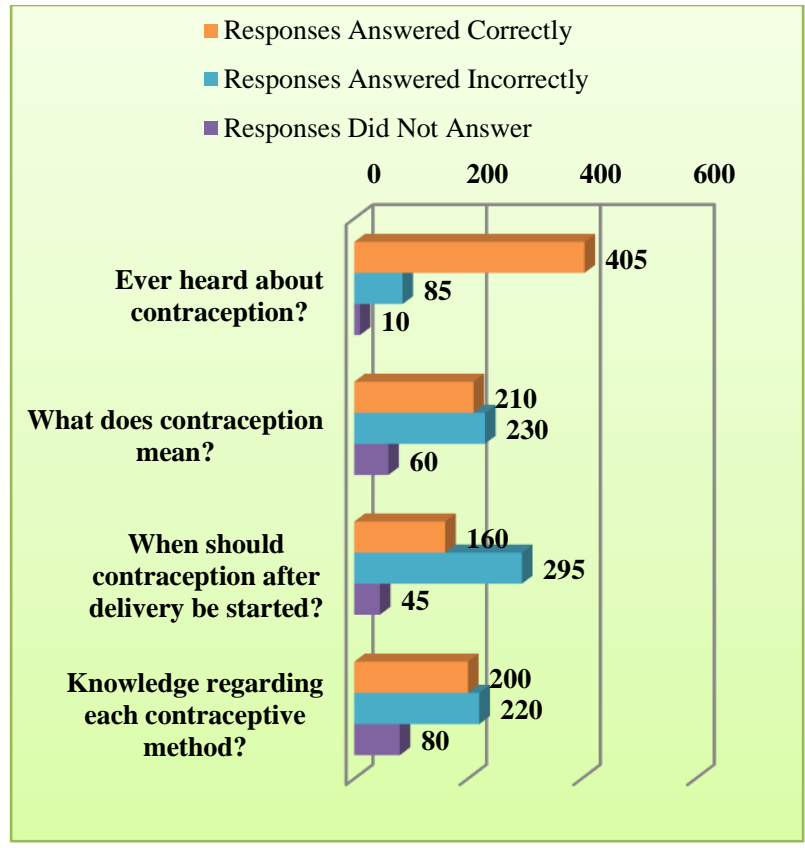

Figure 5: Responses of participants to questionnaire on knowledge about contraception.

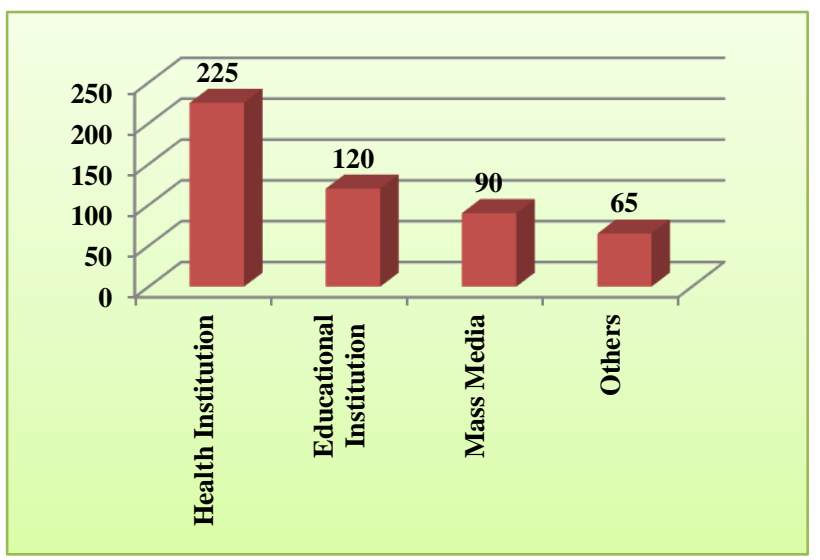

Figure 6: What is the source of information regarding contraception?

$16 \%$ participants were undecided about the choice of contraception method. $380(76 \%)$ participants showed willingness to use contraception and 240 (48\%) participants approved of small family.

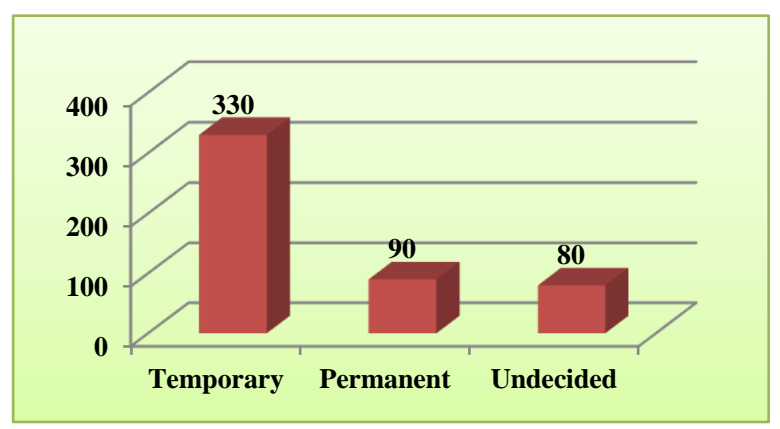

Figure 7: Choice of method in the future? 
$104(27.4 \%)$ and 98 (25.8\%) participants used contraception due to financial and health reasons respectively. $71(18.7 \%)$ and $40(10.5 \%)$ participants used contraception due to husband and for child spacing respectively. $28(7.4 \%), 24(6.3 \%)$ and $15(3.9 \%)$ participants used contraception on doctor's advice, as mother worked outside the household and others reasons respectively. $26(21.7 \%)$ and $24(20 \%)$ participants did not use contraception due to unbearable side effects and for want of more children respectively. 22 (18.3\%) participants did not use contraception due to financial difficulties and $21(17.5 \%)$ participants felt it was useless. $15(12.5 \%)$ and $12(10 \%)$ participants did not use contraception as they was no awareness and others reasons respectively. 380 (76\%) participants had used contraceptive method in the past of which $90(18 \%)$ participants had complaints regarding the previous method of contraception (Figure 8). $240 \quad(48 \%)$ participants used contraceptive methods frequently while $140(28 \%)$ participants used it occasionally (Figure 9).

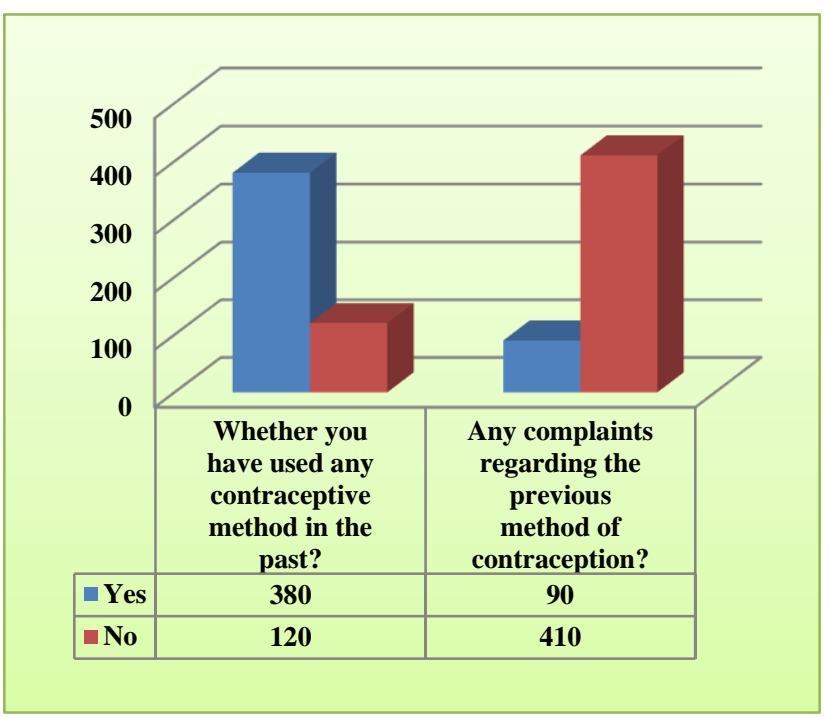

Figure 8: Responses of participants to questionnaire on practice of contraception

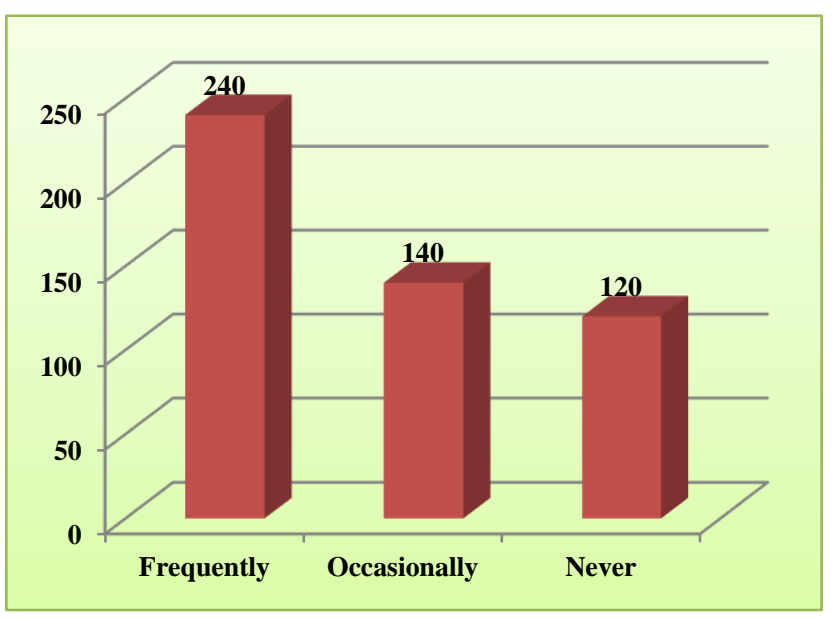

Figure 9: Frequency of use of contraceptive methods.
$55(11 \%)$ and $75(15 \%)$ participants discontinued use of contraceptive methods due to menstrual side effects and aspiration to have a child respectively. 140 (28\%) and $110(22 \%)$ participants discontinued due to religious views and lack of family/husband's approval respectively (Figure 10).

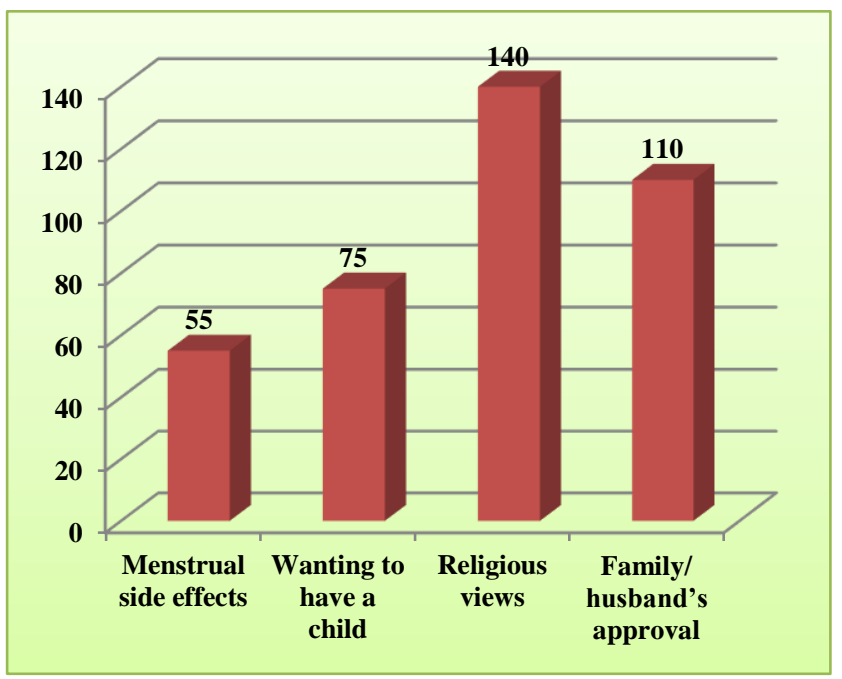

Figure 10: Reasons for discontinuation.

The odds ratio (OR) is one of several statistics that have become increasingly important in clinical research and decision-making. It is particularly useful because as an effect-size statistic, it gives clear and direct information to clinicians. The odds ratio (OR) measures the ratio of the odds that an event or result will occur to the odds of the event not happening. It was observed that age, education and mode of delivery were the significant factors. There was no statistical significance of socioeconomic profile, residential area, booking status, parity and gestational age at delivery (Figure 11).

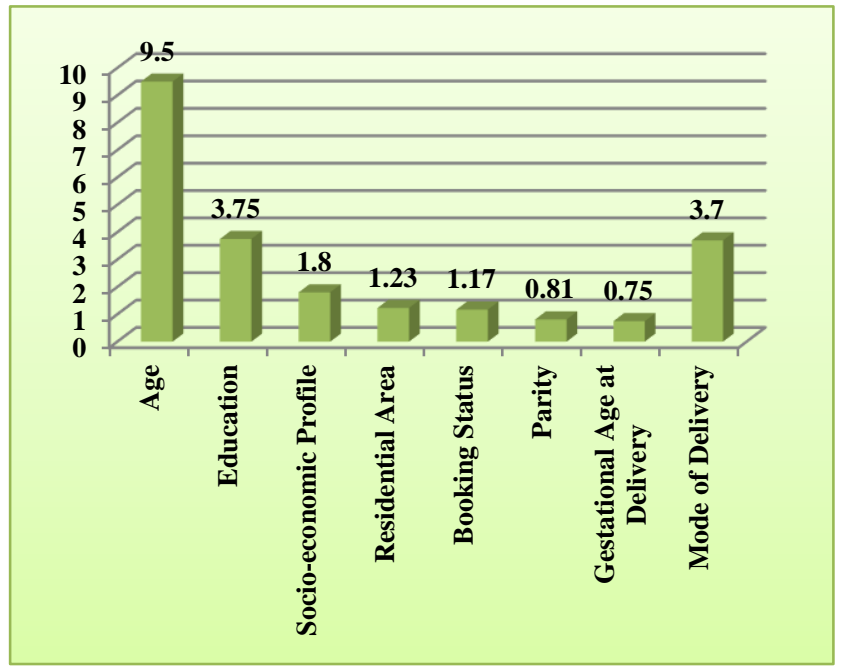

Figure 11: Association of parameters with knowledge of contraception and relationship with attitude and practice of contraception. 


\section{DISCUSSION}

A hospital-based study was conducted with 500 breast feeding mothers to assess the knowledge, attitude and practice regarding contraception among breast feeding mothers. In the present study, majority of the participants $(72 \%)$ were in the age group of 21-25 years followed by $20 \%$ in the age group of $26-30$ years, $4.4 \%$ in the age group of $\geq 30$ years and $3.6 \%$ in the age group of $\leq 20$ years. This is similar to the study of Sherpa SZ et al. ${ }^{11}$

In present study, $21.2 \%$ of the study group was educated upto primary level while $33.2 \%$ and $18.4 \%$ of the participants studied till SSC and HSC respectively. $15.2 \%$ of the study population was graduates and $12 \%$ participants had no education. Majority of participants were from middle class $(50 \%)$ followed by lower class (36.4\%) and upper class (13.6\%). 69.6\% participants resided in rural areas while $30.4 \%$ participants were from urban areas. This is comparable to the studies of Sherpa SZ et a, Pal AC et al, Ekpenyong CE et al, Rao BS et al, Mahawar P et al and Santoso IB et al. ${ }^{11-16}$ It was observed in present study that $410(82 \%)$ participants were booked cases while 90 (18\%) participants were unbooked cases. $230(46 \%)$ participants were primigravida while 270 (54\%) participants were multigravida. Majority of the participants (93.2\%) were between 37-41 weeks of gestational age at delivery followed by $6 \%$ participants in $<37$ weeks and $(0.8 \%)$ participants in $>41$ weeks.

Delivery route in present study was Vaginal in $38.8 \%$ cases and Caesarean Section was performed in $61.2 \%$ cases. $81 \%$ participants had heard of contraception of which $42 \%$ knew what contraception means. 32\% participants were aware of when contraception after delivery should be started. $40 \%$ participants correctly answered about different contraceptive methods. This is concordant to the study of Mahawar P et al. ${ }^{15}$

It was observed in the present study that $45 \%$ participants knew about contraception from the health institution while $24 \%$ and $18 \%$ participants heard about it from educational institution and mass media respectively. $13 \%$ participants knew about contraception from others. These findings were consistent with the studies of Ekpenyong CE et al, Sherpa SZ et al, Mahawar P et al and Santoso IB et al. ${ }^{11-16}$

In present study, $66 \%$ and $18 \%$ participants had said they would select temporary and permanent contraception method while respectively. $16 \%$ participants were undecided about the choice of contraception method. This is in concordance to the studies of Mahawar $\mathrm{P}$ et al, Sherpa SZ et al and Ekpenyong CE et al. ${ }^{11,13,15}$

In the present study, $380(76 \%)$ participants showed willingness to use contraception and $240 \quad(48 \%)$ participants approved of small family. 104 (27.4\%) and 98 (25.8\%) participants used contraception due to financial and health reasons respectively. 71 (18.7\%) and
$40(10.5 \%)$ participants used contraception due to husband and for child spacing respectively. 28 (7.4\%), 24 $(6.3 \%)$ and $15(3.9 \%)$ participants used contraception on doctor's advice, as mother worked outside the household and other reasons respectively. Rao BS et al and Mahawar P. et al noted similar observations in their studies. ${ }^{14,15}$ It was observed in present study that 26 $(21.7 \%)$ and 24 (20\%) participants did not use contraception due to unbearable side effects and for want of more children respectively. $22(18.3 \%)$ participants did not use contraception due to financial difficulties and 21 (17.5\%) participants felt it was useless. $15(12.5 \%)$ and $12(10 \%)$ participants did not use contraception as they was no awareness and others reasons respectively. This is consistent with the studies of Sherpa SZ et al and Santoso IB et al. ${ }^{11,16}$ It was observed in the present study that 380 (76\%) participants had used contraceptive method in the past of which $90(18 \%)$ participants had complaints regarding the previous method of contraception. 240 (48\%) participants used contraceptive methods frequently while $140(28 \%)$ participants used it occasionally. 55 (11\%) and $75(15 \%)$ participants discontinued use of contraceptive methods due to menstrual side effects and aspiration to have a child respectively. 140 (28\%) and $110(22 \%)$ participants discontinued due to religious views and lack of family/husband's approval respectively. This is similar to the study of Rao BS et al. ${ }^{14}$

The odds ratio (OR) is one of several statistics that have become increasingly important in clinical research and decision-making. It is particularly useful because as an effect-size statistic, it gives clear and direct information to clinicians. The odds ratio (OR) measures the ratio of the odds that an event or result will occur to the odds of the event not happening. It was observed in present study that age, education and mode of delivery were the significant factors. There was no statistical significance of socio-economic profile, residential area, booking status, parity and gestational age at delivery. Similar observations were noted in the studies of Sherpa SZ et al, Pal AC et al, Ekpenyong CE et al, Rao BS et al and Santoso IB et al. ${ }^{11-16}$

\section{CONCLUSION}

Post-partum women form a key audience who will be receptive to contraceptive advice. Imparting correct knowledge at correct time can easily motivate them for adoption of proper family planning method. Unfortunately, still the decision of using a contraceptive method is in the hands of elders or on husbands. Thus, it is good that a combined family approach should be followed by authorities to counsel people. As our target population which is currently women only cannot suffice to apply family planning methods in Indian scenario. The current urban phenomenon of nuclear family, where elders will not interfere is good for controlling population explosion. As the government gives incentives to couples who opt for permanent sterilization, which is an effective drive, it should also give incentives to couples who 
follow temporary methods and delay pregnancies. Couples who adopt one child norm or 2 children norm should be encouraged by benefits either in the form of children's education or health insurance.

Funding: No funding sources

Conflict of interest: None declared

Ethical approval: The study was approved by the Institutional Ethics Committee

\section{REFERENCES}

1. Tsui AO, Wasserheit JN, Haaga JG. Reproductive health in developing countries: Expanding dimensions, building solutions (Panel on Reproductive Health, Committee on Population, Commission on Behavioral and Social Sciences and Education, National Research Council). Washington, DC: National Academy Press, 1997.

2. Truitt ST, Fraser AB, Grimes DA, Gallo MF, Schulz KF. Combined hormonal versus nonhormonal versus progestin-only contraception in lactation. Cochrane Database Syst Rev. 2003;2:CD003988.

3. Truitt ST, Fraser AB, Gallo MF, Lopez LM, Grimes DA, Schulz KF. Combined hormonal versus nonhormonal versus progestin-only contraception in lactation. Cochrane Database System Rev. 2003(2).

4. Conde-Agudelo A, Belizán JM. Maternal morbidity and mortality associated with interpregnancy interval: cross sectional study. BMJ. 2000;321(7271):1255-9.

5. Park JE. Park's Textbook of Preventive and Social Medicine, 20th edition 2009, p421.

6. Dabral S, Malik SL. Demographic Study of Gujjars of Delhi: IV. KAP of Family Planning. J. Hum. Ecol. 2004;16(4):231-7.

7. Park K. Social and Preventive Medicine. India: Bhanot Publishers, 2015.

8. India at Glance - Population census 2011. Census organization of India, 2011. Accessed: 2015.
9. Post-partum. IUCD reference manual. New Delhi: Family Planning Division, Ministry of Health and Family Welfare, Government of India, 2010.

10. Leete R, Alam I. Asias demographic miracle: 50 years of unprecedented change. Asia-Pacific Populat J. 1999;14(4):9-20.

11. Sherpa SZ, Sheilini M, Nayak A. Knowledge, Attitude, Practice and Preferences of Contraceptive Methods in Udupi District, Karnataka. J Fam Reproduct Health. 2013;7(3):115-20.

12. Pal AC, Mukhopadhyay DH. Knowledge, Attitude and Practice of Breastfeeding in a Rural Community of Bankura District, West Bengal, India. IOSR J Dent Med Sci (IOSR-JDMS). 2014;13(11):24-8.

13. Ekpenyong CE, Daniel NE, Uwah AF, Ettebong EO, Ibu JO. Lactational amenorrhoea method of contraception: An in-depth study of awareness, knowledge and practice by breast feeding mothers with unintended pregnancies. Int $\mathrm{J}$ Med Sci. 2013;5(1):6-13.

14. Rao BS, Mathada VC. Awareness and Determinants of Contraceptive use among Nursing Mothers in Bellary, Karnataka. J Clinic Diagnos Res: JCDR. 2016;10(1):QC15-QC19.

15. Mahawar P, Anand S, Raghunath D, Dixit S. Contraceptive knowledge, attitude and practices in mothers of infant: a cross-sectional study. Natl J Community Med. 2011;2:105-7.

16. Santoso IB, Surya R. Knowledge, Attitude, and Practice of Contraception among Pregnant Women in Ende District, East Nusa Tenggara, Indonesia. J South Asian Fed Obstet Gynaecol. 2017;9(2):110-8.

Cite this article as: Shawl AS, Thobbi V. Study of knowledge, attitude and practices of contraception in breast-feeding mothers. Int J Reprod Contracept Obstet Gynecol 2019;8:1473-9. 